\title{
Prediction values for peak expiratory flow rates - much ado about something!
}

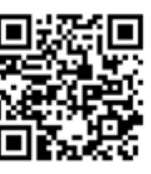

Prediction values for spirometric indices utilise values derived from white populations in resource-rich settings. Traditionally, these are discounted when applied to nonwhite populations. It is encouraging to acknowledge the article by Nokubulwa et al. ${ }^{[1]}$ on prediction values for peak expiratory flow rates (PEFRs) in a Ugandan population.

PEFR may be obtained from an expiratory spirogram or, as is more commonly practised, measured directly using a peak flow meter. Measurement of PEFR is an extremely useful test for the diagnosis and management of asthma, especially in resource-limited settings where spirometry is unavailable or unreliable. In most instances the PEFR is used to monitor asthma control and not frequently used to determine target values for control, as is done for forced expiratory volume in 1 second $\left(\mathrm{FEV}_{1}\right)$. It is not clear why HIV-infected persons and smokers were included in the so-called healthy population, defined in this study as individuals with the absence of respiratory symptoms. It is well known that HIV is associated with chronic obstructive pulmonary disease (COPD). Many HIV-infected persons in developing regions have had at least one episode of tuberculosis (TB), and TB is also associated with COPD. ${ }^{[2]}$

It is also well known through many epidemiological studies that smokers may not have symptoms in the presence of lung disease; there is also the phenomenon of the healthy smoker effect. ${ }^{[3]}$ The study would have been very helpful in understanding the influence of these factors if an additional regression equation had been calculated which excluded these groups, or which interrogated the influence of HIV and smoking in stepwise regression models. In addition, the contribution to the PEFR of the type of floor surface in the homes is unclear. The authors do acknowledge that the influence of these factors will be presented in subsequent publications. However, one cannot accept the prediction equations presented in this article in the absence of this important information.
There is no information on how the mini-Wright PEFR meter was calibrated. One is not informed why the standing posture was used when the PEFR is frequently measured in the sitting position in clinical practice. Of course, there is no significant difference between standing and sitting posture, but in the process of deriving prediction values, as much noise as possible must be eliminated or controlled. ${ }^{[4]}$ The same applies to the time of day the measurements were made. The article would have been more instructive if the derived prediction values for PEFR were compared to currently applied prediction values.

This article serves to underline the value of PEFR in clinical practice and the derivation of regional prediction values enhances its application and relevance. PEFR measurement must be reinforced as a useful, cheap, objective functional measure of asthma control. Like all lung function tests careful attention to technical factors is important when measuring PEFR in clinical practice.

1. Nokubulwa S, Baisley K, Levin J, Nakiyingi-Miiro J, Kamali A, Nunn A. Prediction of peak expiratory flow rate in a Ugandan population. S Afr Respir J 2015;21(4):96-99. DOI:10.7196/SARJ.2015.v21i4.36

2. Van Zyl-Smit RN, Brunet L, Pai M, Yew WW. The convergence of the global smoking, COPD, tuberculosis, HIV, and respiratory infection epidemics. Infect Dis Clin North Am 2010;24(3):693-703. [http://dx.doi.org/10.1016/j.idc.2010.04.012]

3. Becklake MR, Lalloo UG. The 'healthy smoker': A phenomenon of health selection? Respiration 1990;57(3):137-144. [http://dx.doi.org/10.1159/000195837]

4. Lalloo UG, Becklake MR, Goldsmith CM. Effect of standing versus sitting position on spirometric indices in healthy subjects. Respiration 1991;58(3-4):122-125. [http:// dx.doi.org/10.1159/000195911]

\section{Umesh G Lalloo}

Director of the Enhancing Care Foundation, Durban University of Technology, Durban, South Africa

S Afr Respir J 2015;21(4):89. DOI:10.7196/SARJ.2015.v21i4.51 